\title{
Akulturasi Islam dan Tradisi Lokal Kosek ponjen pada Upacara Pernikahan Masyarakat Osing
}

\author{
Wiwik Setiyani ${ }^{*}$, Zakkiyatul Fikriyah ${ }^{2}$, Nasruddin ${ }^{3}$ \\ 1 UIN Sunan Ampel Surabaya, Indonesia; wiwiksetiyani@uinsby.ac.id \\ 2 UIN Sunan Ampel Surabaya, Indonesia; e02217042@uinsby.ac.id \\ UIN Sunan Ampel Surabaya, Indonesia; nasruddin@uinsby.ac.id \\ * Correspondence: soehanadiharisa@gmail.com
}

Received: 2021-01-27; Accepted: 2021-07-15; Published: 2021-08-22

\begin{abstract}
Kosek ponjen is a marriage tradition among Osing society in Banyuwangi. It's interesting to examine the Osing society's believe that this tradition becomes a way to cleanse the groom and bride from various dangers. The groom or bride exclusively performs this ritual if they happened to be their family's youngest son or daughter. This article explains the intersection between Islam and kosek ponjen local tradition during marriage ceremonies. Qualitative research method applies in-depth interview to obtain comprehensive data regarding the marriage ritual. Kosek ponjen could be analyzed using Victor Turner's symbolic meaning theory. This research finds that Osing society implements kosek ponjen as a compulsory ritual during marriage to symbolize an exchange between the parents and the groom and bride to throw upcoming misfortunes away. Symbols being used include rice grains, coins and a carrying pole with an important message for the family. The groom and bride need to trust each other and tolerate each other's shortcomings, seek their parents' acknowledgement and believe in Allah that their family will be harmonious for the rest of their life. Acculturation between Islam and local marriage tradition in Banyuwangi formed a diverse culture rich in moral values in starting a family.
\end{abstract}

Keywords: Acculturation of Islam; Kosek ponjen; Marriage; Osing Society.

Abstrak: Tradisi kosek ponjen merupakan salah satu tradisi pada pernikahan masyarakat Osing di Banyuwangi. Tradisi pernikahan tersebut menarik untuk diteliti karena, terdapat keyakinan dapat membersihkan diri dari segala macam bahaya pada calon pengantin. Ritual ini hanya dikhususkan pada mempelai perempuan atau laki-laki yang lahir terakhir atau anak ragil. Artikel ini menjelaskan titik temu antara Islam dan tradisi lokal kosek ponjen pada upacara pernikahan. Metode peneltian kualitatif dipilih dengan teknik interview yang mendalam. Tujuannya, menemukan data yang komprehensif pada pelaksanaan ritual pernikahan. Tradisi ritual kosek ponjen menjadi kajian menarik yang dapat dianalisis dengan teori makna simbolik Victor Turner. Temuan penelitian, masyarakat Osing menyakini bahwa, kosek ponjen menjadi ritual wajib. Urgensi ritual adalah melaksanakan tradisi pertukaran antara orangtua dan mempelai untuk membuang kesialan atau malapetaka yang dapat mengancam kehidupan kelak. Simbol yang digunakan adalah beras, uang koin dan pikulan yang memiliki pesan penting bagi keluarga. Pasangan pernikahan harus saling percaya dan saling memberi serta menguatkan keyakinan untuk melengkapi dan menyempurnakan kekurangan masing-masing. Mohon restu orangtua dan yakin kepada Allah keberlangsungan keluarga akan harmonis sampai kematian memisahkan diantara keduanya. Akulturasi Islam dan tradisi lokal di Banyuwangi pada tradisi pernikahan dapat membentuk keragaman budaya yang sarat dengan nilai-nilai moral dalam membangun sebuah keluarga.

Kata Kunci: Akulturasi Islam; Kosek ponjen; Masyarakat Osing; Pernikahan. 


\section{Pendahuluan}

Masyarakat Indonesia memiliki ragam tradisi yang tersebar di berbagai daerah. Tradisi lokal menjadi salah satu cerminan masyarakat yang kaya dengan berbagai tradisi. Masing-masing memiliki ciri khas dalam melaksanakan ritual khususnya, pada ritual pernikahan. Kekayaan tradisi tersebut dapat memperkaya pengetahuan tentang perkembangan budaya di Indonesia. Salah satu tradisi lokal adalah pernikahan yang sangat diharapkan bagi pasangan calon suami istri. Pernikahan memiliki ragam cara yang dilakukan sesuai dengan budaya warisan leluhurnya. Pernikahan memiliki tujuan mulia dalam rangka membangun keluarga bahagia dengan berharap diberikan keturunan anak-anak. Sebagaimana Islam mengajarkan akan lahir dari rahim perempuan dan Allah telah menentukan pasangan di antara umat manusia (Alquran, Azzariyat: 51:49). Tradisi lokal dengan Islam tercipta harmoni budaya yang membentuk identitas masyarakat. Tradisi kosek ponjen pada masyarakat Osing di Banyuwangi memiliki hubungan yang erat dengan agama Islam. Masyarakat Osing memiliki fasilitas untuk melaksanakan ritual atau tradisi kosek ponjen tersebut untuk melaksanakan tradisi ritual tersebut (Praditya, 2014).

Penelitian tentang akulturasi Islam dan tradisi lokal telah banyak dilakukan, diantaranya; Karya Ani, Abubakar, \& Iqbal (2019) tentang Akulturasi Islam dalam Perkawinan Adat Dayak Ngaju yang menjelaskan pernikahan adat Dayak yang telah terjadi akulturasi pada tradisi Islam. Tulisan Sumbulah (2012) tentang Islam Jawa dan Akulturasi Budaya: Karakteristik, Variasi Dan Ketaatan Ekspresif; juga mewarnai ekspresi ketaatan orang Jawa dan Islam menembus batas-batas tradisinya. Tulisan Mutawali (2019) yang berjudul Genealogi Islam Nusantara di Lombok dan Dialektika Akulturasi Budaya: Wajah Sosial Islam Sasak; menjelaskan wajah sosial Islam sasak yang di Lombok dan Karya Muasmara (2020) tentang Akulturasi Islam dan Budaya Nusantara yang menjelaskan lebih komprehensif tentang Islam nusantara yang mengakomodasi budaya-budaya lokal bersentuhan dengan Islam, karya-karya tersebut dapat dijadikan pijakan dalam menemukan kerangka akulturasi Islam.

Masyarakat Osing sebagai subjek yang diteliti menjadi informasi penting dengan merujuk pada karya Shultoni (2020) tentang Dialektika Bahasa Jawa Dalam Adat Perang Bangkat Suku Osing Kecamatan Singojuruh yang menjelaskan; pernikahan suku Osing dengan tradisi perang bangkat sebagai simbol. Penelitian lainnya tentang Tata Laksana Upacara Pernikahan Adat Suku Osing di Desa Kemiren Banyuwangi, mendeskripsikan tata laksana upacara pernikahan suku Osing di Kemiren sebagai pengetahuan dan pemahaman tradisi secara luas dan lugas (Sari \& Megasari, 2020). Sementara tulisan Nurullaily (2020) tentang Akulturasi Budaya pada Tata Rias Mupus Braen Blambangan Suku Osing di Desa Kemiren Banyuwangi menjelaskan, tata rias pengantin dalam tradisi Islam suku Osing di Blambangan yang sangat unik terdapat sentuhan Islam. Beberapa penelitian tersebut menjadi referensi dalam menemukan ragam tradisi masyarakat Osing di Banyuwangi yang tentunya sangat berbeda dalam temuan dan komponen rumusan yang digunakan pada masayarakat suku Osing. Peneliti fokus pada tradisi kosek ponjen yang terjadi pada pernikahan masyarakat suku Osing di Banyuwangi.

Akulturasi Islam dan tradisi lokal kosek ponjen menjadi daya tarik peneliti untuk mengungkap rangkaian ritual pada pernikahan. Makna simbolik menjadi pisau analisis untuk mengungkap pesanpesan yang tidak dapat dipahami oleh nalar akal tetapi, mampu menyentuh intuisi paling dalam yakni, keyakinan atau kepercayaan masyarakat. Teori Victor Turner (1967) menjadi pilihan untuk menemukan sisi-sisi penting dengan mengungkap aspek lain dari sebuah simbol ritual. Perspektif teori Levi-Strauss (1989) menjadi pilihan yang tepat guna, melihat aspek-aspek sosial pada teori pertukaran atau exchange theory pasca ritual melahirkan fenomena unik yang bersifat paradigmatik. Tiga hal yang dibahas artikel ini diantaranya; pertama, bagaimana kehidupan sosio-religi masyarakat Osing di Banyuwangi. Kedua, bagaimana ritual kosek ponjen pada tradisi pernikahan dan ketiga, bagaimana titik temu Islam dan tradisi lokal pada ritual tersebut. 


\section{Hasil dan Pembahasan}

\section{Sosio-Religi Masyarakat Osing}

Suku Osing cukup dikenal di Banyuwangi. Masyarakatnya cepat beradaptasi dengan lingkungannya. Suku osing mempunyai ragam budaya dengan karakteristik sinkretis (Ratnawati, Triyanto, \& Syakir, 2019; Yulianingsih, 2020), yakni dapat menyerap dan menerima dengan proses singkat serta mampu memproduksi kembali budaya Osing. Suku Osing di Banyuwangi menempati beberapa kecamatan di antaranya; Desa Kemiren, Rogo jampi, Sempu, Glagah dan masih banyak lagi. Kata Osing memiliki makna "tidak". Laros atau lare Osing atau wong Blambangan merupakan sebutan yang diinginkan masyarakat Blambangan (Cipta, 2020). Nilai sejarah dari suku Osing adalah Blambangan yang tidak mau bekerjasama dengan Belanda (Relin, 2017).

Pola komunikasi masyarakat Osing dipengaruhi nilai dan norma yang terkandung dalam bingkai lembaga tradisionalnya. Varian Bahasa yang digunakan didasarkan pada setting masyarakat dengan pola tutur kata keakraban yang bersifat egaliter (Serikit, 2009). Pola komunikasi masyarakat yang akrab dengan siapapun maka, memiliki peluang cepat untuk berkembang dengan pola adaptasi. Komunikasi masyarakat Osing mengutamakan bahasa lokalnya. Strategi komunikasi yang dilakukan adalah dengan menggunakan bahasa Osing sebagai alat komunikasi sehari-hari. Selain itu, bahasa Osing digunakan sebagai muatan lokal materi pembelajaran di sekolah (Arista, 2015; Toenlioe \& Soepriyanto, 2017).

Ekonomi masyarakat Banyuwangi memiliki potensi sumber kekayaan alam yang melimpah. Analisis ekonomi masyarakat Banyuwangi pada prioritas utama adalah sektor pertanian (Ayubi, 2014). Perekonomian tersebut didukung dengan faktor ekonomi lainnya, seperti; perdagangan, nelayan dan lain sebagainya. Kehidupan nelayan suku Osing dapat berproses dengan cepat pada masyarakat pantai dengan melakukan perjalanan sampai selat Bali (Kusnadi, Sunarlan, \& Sariono, 2019). Perjuangan hidup masyarakat nelayan Osing semakin mengukuhkan ketahanan dan kemandirian dalam menemukan cara yang tepat untuk memenuhi kebutuhan hidupnya.

Aspek pendidikan masyarakat Osing masih diperlukan peningkatan karena, masih banyak anakanak yang putus sekolah. Peran pemerintah Banyuwangi dalam menyiapkan generasi muda jangan sampai putus sekolah diberikan beasiswa agar, mampu melanjutkan sekolahnya (Kholiq, 2019). Program pemerintah dengan paket A, B, C serta kartu Indonesia pintar (KIP) menjadi solusi kreatif untuk menanggulangi anak-anak putus sekolah. Aspek budaya di Banyuwangi menjadi mendukung pengembangan pariwisata (Fahad \& Endrayadi, 2017). Pariwisata memiliki peran penting dalam rangka pengembangan wilayah guna, menarik investor dan turis domestik maupun asing. Kesiapan pariwisata di setiap daerah di warnai dengan ragam tradisi yang dimiliki suku Osing. Tradisi lokal masyarakat Osing menjadi satu identitas yang kaya dengan coraknya sehingga, menarik para pengunjung. Suku osing memiliki permainan tradisional yang terus dilestarikan oleh masyarakatnya seperti; temeker, santalan dan teong-teongan (Anam, Ovaleoshanta, Ardiansyah, \& Santoso, 2017), permainan tersebut mampu membangun pola interaksi masyarakat Osing. Nilai- yang terkandung dari permainan tradisi tersebut yakni, melatih kesabaran, kerjasama dengan tim dan strategi untuk meraih kemenangan.

Suku Osing memiliki hubungan kuat dengan orang-orang Jawa Timur dalam hal budaya (Ainiyah, 2016). Hubungan antara jawa dengan suku Osing yang kuat tersebut, tidak dapat dipungkiri bahwa Islam Jawa dengan Islam Osing memiliki satu rumpun konsep Pemikiran. Setiap agama besar yang masuk di suatu daerah tentunya akan berhubungan dengan budaya lokal daerah tersebut. Islam Jawa yang telah dijelaskan diatas, yakni dengan tanpa menghilangkan suatu kultur budaya yang ada dan ajaran agama Islam. Namun, Islam Jawa memasukkan ajaran agama Islam dalam kultur budaya yang ada. Konsep tersebut tidak jauh beda dengan Islam Osing yang mana suku Osing kaya akan budaya yang dilakukan masyarakat secara turun menurun, hal tersebut tidak dihilangkan dengan masuknya agama Islam pada masyarakat Osing. Namun, Islam Osing menerapkan ajaran-ajaran Islam ke dalam kultur budaya yang ada. Hal tersebut yang disebut dengan akulturasi budaya. 
Masyarakat Osing memiliki tradisi lisan yang disebut basanan (tutur kata bahasa Osing). Tradisi lisan basanan ini tetap dipraktikkan untuk menjaga kelestariannya (Istiqomah, 2020; Syuhadak, 2016). Tradisi masyarakat Osing memiliki praktik pendidikan berbasis kearifan lokal yang harus dipedomani sebagaimana tradisi lisan basanan. Nilai-nilai yang terkandung adalah tentang wacana aksara lisan yang harus dijaga dan dirawat agar, tidak mudah pudar. Pada aspek sosial masyarakat Osing senantiasa bekerjasama untuk terus melakukan perubahan yang lebih baik. Perubahan sosial menjadi strategi dalam rangka mendukung kemajuan pariwisata. Masyarakat Osing membentuk agen perubahan yakni, membentuk kelompok-kelompok kerja sebagai mediator dalam menggerakkan wisata budaya di Banyuwangi (Nursafitri, Pageh, \& Wirawan, 2020). Agen perubahan yang dimaksud melibatkan seluruh komponen masyarakat dari hulu hingga hilir dengan saling mendukung program wisata yang menjadi icon masyarakat.

Aspek sosial budaya menjadi dua bidang yang saling melengkapi yakni, pada budaya minum kopi masyarakat Osing menjadi proyek transnasional dari zaman penjajahan hingga kini. Budaya ini menjadi festival baru yang diberi nama "kopi sepuluh ewu" budaya gastro Kosmopolitan (Zulfikar, 2020). Masyarakat suku Osing dihadapkan pada kekuatan transnasional yang tidak hanya dilakukan oleh suku Osing tetapi, benar-benar merambah pada dunia global yakni, pihak-pihak luar daerah bahkan pihak asing. Budaya minum kopi menjadi sensasi masyarakat suku Osing yang di setiap seduhan kopinya menawarkan platform konsumerisme global yang kreatif.

Penyebutan kata Osing sebenarnya bukan lahir dari budaya lokal Blambngan, akan tetapi disebabkan oleh persoalan politik yang berimplikasi pada rakyat Blambangan. Menurut Stoppelaar (1927) dan Scholte (1927) sebutan "Osing atau Using" yang berarti tidak, diberikan oleh masyarakat migran asal Jawa Tengah di daerah Banyuwangi Selatan. Setengah masyarakatnya mengalami keberatan atas penamaan yang dasarnya sangat sederhana (Ainiyah, 2016). Sebutan Osing tersebut muncul setelah terjadi perang Bayu guna membedakan antara penduduk migran Jawa dengan Madura. Lepas dari asal-usul penyebutan kata Osing yang pada akhirnya orang Banyuwangi menerima sebutan tersebut, bahkan menjadi identitas lokal yang kuat dan menjadi pembeda dengan Jawa.

Pada aspek agama masyarakat Osing merupakan masyarakat yang taat terhadap ajaran agama. Suku Osing dalam kontek sejarah yang ditulis Andrew Betty (1999), masyarakat suku Osing merupakan keturunan kerajaan Blambangan, pada abad-19 terjadi proses Islamisasi. Islam mengalami proses adaptasi dengan cepat khususnya orang-orang pendatang dari wong kulonan; Mataraman, Bugis, Melayu, Mandar dan Madura. Perkembangan Islam di Banyuwangi tidak diketahui secara pasti namun, Islam mengalami pertumbuhan yang pesat dan terjadi proses akulturasi budaya yakni, Islam dengan tradisi lokal.

Islam lokal di Banyuwangi melaksanakan ragam aktivitas seperti, nisfu sya'ban setiap tanggal 15 ruwah. Penggunaan kalender Islam yang secara mengalir menjadi kebiasaan bagi masyarakat Osing. Internalisasi tradisi lokal suku Osing memberikan warna baru bagi pengembangan tradisi Islam di Banyuwangi. Di era digital harus mampu mengikuti perkembangan zaman. Salah satu bentuk revitalisasi Islam Nusantara adalah melakukan ekspos foto kegiatan kyai yang dapat memberikan nilai maslahah bagi masyarakat (Mukodi, 2020). Fenomena masyarakat Osing mengalami proses perubahan signifikan, baik pada aspek ekonomi, sosial, budaya dan agama yang mampu beradaptasi dengan cepat serta taat terhadap ajaran Agama.

Pesantren di Banyuwangi memiliki peran penting dalam pemberdayaan ekonomi kreatif (Cholida, Wahyuni, \& Widodo, 2020). Pesantren harus menciptakan prestasi dengan produk unggulannya. Strategi transformasi pesantren adalah menjadi pusat kewirausahaan, diharapkan dapat menciptakan lapangan pekerjaan dan meningkatkan kesejahteraan.

Sosio religi masyarakat Osing di Banyuwangi adalah gambaran masyarakat yang adaptif. Potensipotensi kekayaan alam mampu diorganisir secara massif, peran-peran masyarakat yang proaktif terhadap setiap perubahan social (Cholida et al., 2020) menjadi modal besar untuk mewujudkan kemakmuran. Peran tokoh masyarakat pada level struktural dan peran Kiai di pesantren dari hulu hingga hilir bertekad mencapai kemajuan dan kesejahteraan masyarakat. Pencapaian kesejahteraan 
dilakukan dengan membangun sinergitas di berbagai bidang diantaranya; pendidikan, ekonomi, sosial, budaya dan agama.

\section{Kosek ponjen pada Ritual Pernikahan dan Titik Temu Akulturasi Islam}

Genealogi ritual pernikahan pada masyarakat Osing adalah bermula dari kisah atau cerita para orangtua. Strategi masyarakat suku Osing dalam melestarikan adat istiadat adalah tradisi pernikahan, merupakan hukum adat yang harus diikuti oleh masyarakat Osing (Rofikoh, 2018). Pernikahan memiliki tradisi yang tidak bisa ditinggalkan karena, terdapat kepercayaan terhadap ritual tersebut. Ritual yang dimaksud adalah kosek ponjen, istilah yang digunakan pada ritual pernikahan. Kosek ponjen disebut juga dengan tumplek ponjen, artinya; mencurahkan atau memberikan seluruh kasih sayangnya dan hartanya untuk mempelai pengantin (Muslih, Komunikasi Personal, 17 Desember 2020). Tradisi pernikahan ini hanya diberlakukan pada anak kemunjilan atau anak terakhir dalam keluarganya.

Konsep ritual kosek ponjen merupakan warisan para leluhur masyarakat Osing yang diawali dengan perang bangkat pada upacara pernikahan (al Asyari \& Sugihartini, 2019). Rangkaian ritual kosek ponjen mewarnai tradisi suku Osing yang terus dilestarikan bahkan, mampu menarik wisata masyarakat domestik dan asing. Tradisi lokal di Banyuwangi khususnya suku Osing memberikan kontribusi bagi perkembangan budaya lokal. Kegiatan ritual tersebut terjadi sebagai bentuk modifikasi tradisi yang diwariskan secara turun temurun.

Inisiator ritual kosek ponjen tidak dapat diketahui secara pasti, ritual ini telah mentradisi secara turun temurun dan menarik perhatian masyarakat untuk diyakini dan dilaksanakan. Keyakinan terhadap tradisi kosek ponjen telah mendarah daging ke anak cucunya sehingga, menjadi kegiatan ritual wajib yang memiliki relasi antara agama dan spiritualitas di era saat ini (Najoan, 2020). Prosesi kosek ponjen dilakukan pada pernikahan anak terakhir baik laki-laki atau perempuan ataupun orangtua yang memiliki satu anak.

Alasan orang tua melakukan ritual kosek ponjen adalah untuk mencurahkan seluruh apa yang yang dimiliki untuk ditumpahkan dan sebagai tugas/nggawe terakhir. Media yang digunakan terdiri dari picis ponjen (uang ponjen) yang akan dikosek dengan beras kuning. Pikulan ponjen dan bantal kloso sebagai alat-alat pendukung untuk pelaksanaan ritual kosek ponjen (Agus, Komunikasi Personal, 22 November 2020). Perlengkapan ritual memiliki simbol-simbol yang memiliki makna bagi yang melaksanakan ritual (Busro \& Qodim, 2018; Busro, Yuliyanti, Syukur, \& Rosyad, 2020; Olang, Susanti, \& Risca, 2020).

Tata cara pelaksanaan ritual kosek ponjen dilakukan dengan cara runtut diantaranya; Pertama, salah satu dari keluarga mempelai mengeluarkan engkrak (pikulan) beserta isinya, dan bantal kloso diletakkan di tempat pelaksanaan. Pemimpin memulai tradisi dengan mengatakan maksud atau makna dari beberapa barang yang berada di engkrak dan juga makna bantal kloso. Proses tradisi telah diwariskan secara turun temurun dengan maksud dan tujuan sebagaimana yang diinginkan (Hindaryatiningsih, 2017).

Kedua, Pemimpin tradisi memulai Kosek ponjen dengan bacaan "Bismillahirrahmanirrahim". Pemimpin menaruh picis ponjen ke sebuah nampan yang berisikan beras kuning. Ketiga, Perwakilan dari keluarga mempelai putri dan putra maju ke depan. Kemudian, kedua orang tersebut beserta kedua mempelai mengosek atau mengaduk-aduk isi nampan. Bacaan basmallah saat mengawali ritual diartikan sebagai ungkapan bahwa, yang dilakukan adalah atas nama Allah yang diharapkan mendapatkan perlindungan dari Allah yang menciptakan alam semesta (Oetomo, 2020).

Keempat, kedua mempelai mengosek atau mengaduk isi nampan, hingga picis atau uang yang ada di dalamnya keluar. Dimana kedua mempelai berebut untuk saling mengeluarkan uang yang ada di dalam nampan. Kemudian, setelah uang yang ada di dalam nampan habis, pemimpin akan mengatakan siapa yang paling banyak mengeluarkan uang dari dalam nampan. Inti kosek ponjen adalah saat kedua pasangan mengeluarkan uang koin paling banyak dimaknai sebagai sedekah untuk mendapatkan keberkahan pernikahan (Haq, 2019). Pasangan hidup yang mendapatkan kebahagiaan dan kenikmatan hidup. 
Kelima, acara telah usai, pemimpin tradisi upacara kosek ponjen menutup dengan pembacaan doadoa Islam dengan menggunakkan bahasa arab bercampur dengan bahasa Osing. Modifikasi doa dengan ragam Bahasa diharapkan dapat memahami makna dari doa yang dibacakan (Dewi, 2018). Sinkretisme dalam perspektif Geertz (1960) di antaranya mengkomunikasikan antara tradisi lokal dengan Islam

Doa-doa yang dipanjatkan pada saat ritual menggunakan doa-doa yang diajarkan dalam Islam yang menjelaskan bahwa, pelaksana ritual adalah seorang muslim yang menyakini ke-Esaan Tuhannya. Titik temu antara tradisi lokal dengan Islam pada acara kosek ponjen merupakan bentuk akulturasi Islam (Ani et al., 2019). Alat-alat yang digunakan dalam ritual yang disebut dengan istilah kosek ponjen pada masyarakat Osing menunjukkan sebagai identitas tradisi lokal. Akulturasi Islam dalam teori Geertz dalam perspektif ritual kosek ponjen tidak menjelaskan bagian-bagian mana yang diadaptasikan tetapi, pada rangkaian acara ritual menyertakan doa-doa ajaran Islam. Penyertaan doa ajaran Islam sebagai bentuk ketaatan terhadap ajaran agama melebihi tradisi lokal yang dilaksanakan (Elma, Komunikasi Personal, 20 November 2020). Pengakuan masyarakat terhadap aktivitas tersebut menjelaskan bahwa, tradisi lokal kosek ponjen dapat dijadikan sebagai budaya lokal yang dapat dinikmati masyarakat pada acara pernikahan.

Tradisi lokal kosek ponjen merupakan tradisi lokal yang sudah ada sejak zaman nenek moyang, namun kehadiran agama Islam pada masyarakat Osing merupakan bentuk penerimaan nilai-nilai yang baru kedalam sebuah budaya yang sudah terbentuk sebelumnya. Tanpa menghilangkan dan meruntuhkan budaya yang sudah ada, masyarakat suku Osing mengimplementasikan kedua budaya dalam kehidupan sosial. Terkadang pertemuan dua budaya memungkinkan terjadi suatu ketegangan, bahkan dapat memicu terjadinya peperangan. Namun dalam kasus pertemuan antara budaya masyarakat Osing dengan ajaran Islam justru terjadi suatu perpaduan yang saling menguntungkan. Proses akulturasi yang berjalan dengan beriringan melahirkan sebuah integrasi dalam masyarakat. Budaya Islam Arab yang hadir tidak diterima dengan mudah sebagaimana aslinya, tetapi dilakukan penyesuaian dengan ritual-ritual yang sudah ada dalam tradisi lokal. Selama hal tersebut tidak bertentangan dengan nilai-nilai keagamaan dalam Islam, maka tradisi lokal tersebut tetap dilakukan dengan menyesuaikan ajaran agama secara beriringan. Identitas lokal yang diwariskan secara turunmenurun tidak dihilangkan dengan adanya penerimaan agama Islam di masyarakat, namun penyatuan terjadi saat adanya pengakuan dari masyarakat terhadap kehadiran dua budaya.

Masuknya agama Islam dengan membawa hal baru bagi kebudayaan suku Osing kemudian mempengaruhi budaya lokal yang ada. Tetapi perubahan budaya yang terjadi pada masyarakat merupakan penyesuaian pandangan antara pengakuan kebenaran agama yang diterima dengan tradisi lokal. Sikronisasi dan keselarasan antara budaya lokal dengan ajaran Islam dapat digandengkan atas pertimbangan masyarakat sebagai pelaku. Ritual kosek ponjen terdapat titik temu Islam yang dapat dimaknai sebagai akulturasi (Muasmara \& Ajmain, 2020). Peralatan dan tata acara pelaksanaan kosek ponjen hanyalah media komunikasi yang menjelaskan cara manusia berbagi atau bersedekah melalui simbol-simbol. Tradisi Jawa yang lekat dengan media alam atau seperangkat alat memiliki maknamakna tertentu yang diyakini masyarakat (Basyir, 2018). Masyarakat suku Osing melakukan tradisi yang sudah ada sejak zaman nenek moyang dengan memasukkan ajaran agama Islam dalam budaya lokal, dimana hal tersebut masih dilakukan hingga saat ini.

Masyarakat Osing memiliki pandangan yang mempengaruhi kehidupannya pasca pelaksanaan ritual. Memaknai ritual bagi orangtua dan pasangan yang menikah dapat merasakan kehidupan baru yang terlepas dari kesulitan hidup yang akan dihadapinya. Perubahan sikap berdampak pada perubahan sosial (Nursafitri et al., 2020) yang dialami pasca ritual, dapat memberikan kontribusi bahwa, ritual kosek ponjen memberikan pengaruh pada psikologis pelakunya.

Makna ritual memberikan dampak perubahan pada perilaku masyarakat pasca ritual, tidak hanya pada pasangan yang melaksanakan ritual kosek ponjen tetapi, juga bagi masyarakat yang mengikuti upacara tersebut. Perubahan pada sikap masyarakat yang dirasakan bahwa, tradisi kosek ponjen mendapatkan penerimaan yang berkesan bagi masyarakat. Tidak ada larangan bagi Islam melaksanakan tradisi adalah acara muamalah atau relasi antar manusia untuk membangun 
kebersamaan dalam bingkai tradisi. Inklusivisme Islam inilah yang dapat menyatukan pembangunan (Rahman \& Saebani, 2018) melalui tradisi lokal yang berkembang di masyarakat Osing Banyuwangi.

\section{Hubungan Timbal Balik Pada Pertukaran Simbol Sebagai Pelepasan keburukan}

Tradisi lokal kosek ponjen merupakan hubungan timbal balik yang dilakukan orangtua dan pasangan pengantin. Simbol-simbol yang digunakan pada tradisi kosek ponjen merupakan alat-alat yang berfungsi penting bagi pengantin sebagaimana analisis simbol victor Turner (John, 2008) menjadi salah satu exegetical meaning bahwa, makna simbol diperoleh dari informan yang melaksanakan ritual kosek ponjen (Mufrihah, 2018).

Peralatan yang digunakan pada ritual kosek ponjen merupakan simbol-simbol yang memiliki hubungan timbal balik bagi pelaksana ritual. Turner (1967) menjelaskan bahwa, simbol merupakan bagian terkecil dari sebuah ritual yang memiliki makna yang dalam. Ciri Khas dari simbol diantaranya: multivocal, polarisasi dan unifikasi. Multivokal menjelaskan adanya kekayaan makna dari sebuah simbol yang mengarah banyak sesuatu hal. Polarisasi adalah pemisahan dari setiap simbol yang digunakan memiliki makna berbeda-beda. Dan unifikasi menjelaskan setiap simbol yang digunakan memiliki nilai-nilai keunikan yang khas (Mufrihah, 2018).

Membuat dan memberikan sesuatu untuk acara ritual memiliki pesan moral bagi orangtua dan pasangan pernikahan. Pesan moral dalam ritual adalah rasa bangga dan pengharapan apa yang telah dilakukan dalam ritual kosek ponjen sebagai bentuk polarisasi atau pemisahan dari sesuatu yang buruk akan hilang. Keyakinan masyarakat terhadap ritual memiliki nilai-nilai tradisi yang tidak diabaikan. Pola komunikasi dengan budaya lokal dapat membentuk identitas masyarakat yang kaya dengan tradisi lokal (Hidayatullah, 2020).

Makna simbol dari sebuah ritual sebagai hubungan timbal balik yang dapat memberikan rasa nyaman bagi orangtua dan pasangan pernikahan. Interaksi dengan masyarakat melalui tradisi kosek ponjen dalam perspektif Levi-Strauss dapat dijustifikasi sebagai pertukaran sosial atau exchange theory (Levi-Strauss, 1989). Ritual kosek ponjen pada masyarakat Osing merupakan bentuk pertukaran sosial yang membawa perubahan bagi masyarakat. Warna kehidupan masyarakat menjadi lebih bermakna dengan tradisi lokal yang dilakukan masyarakat pada acara pernikahan anak terakhir.

Makna simbol dalam pelaksanaan ritual merupakan dialog partnership yang dilakukan oleh orangorang tertentu dan terbatas. Masyarakat Osing menjadi subjek sekaligus berkontribusi terhadap pelestarian tradisi lokal yang memiliki makna pada persamaan dan keseimbangan. Pelaksanaan ritual membangun integrasi antar orang-orang yang berbeda suku dan Bahasa sebagaimana terjadi pada masyarakat Banyuwangi. Pertukaran terbatas atau restricted exchange pada suku Osing menjadi identitas masyarakat Banyuwangi yang dapat menjadi komodifikasi ritual untuk menjaga tradisi lokal (Lubis \& Rohmatillah, 2019). Ritual kosek ponjen menjadi komodifikasi masyarakat Osing yang dapat menarik perhatian masyarakat.

Hubungan timbal balik pada pertukaran simbol memiliki makna bagi pelaku orangtua dan pasangan yang sedang menikah. Komitmen yang dibangun untuk mendapatkan kebahagiaan dan kelancaran dalam berkeluarga ditandai dengan menumpahkan seperangkat alat-alat pada ritual yang berupa beras kuning dan uang koin yang di-kosek. Konstruksi budaya menggambarkan pertukaran perilaku masyarakat yang memiliki dua tipologi yakni, pertukaran ekonomi dan sosial. Pasca menikah kebutuhan ekonomi semakin menempati posisi penting dan relasi sosial menjadi dampak dari pertukaran sosial (Ashley, 1990).

Pertukaran sosial pada simbol-simbol ritual sebagai bentuk membuang keburukan yang melekat pada keluarganya. Keyakinan bahwa, manusia memiliki sisi keburukan dan dengan ritual maka, akan hilang adalah sebuah generalized exchange yang dipastikan masyarakat sepakat dengan keyakinan tersebut. Membuang kesialan atau keburukan menjadi keharusan bagi masyarakat karena, dapat menghambat keberlangsungan kehidupan keluarga. Solidaritas dan komitmen yang kuat untuk menuju kebahagiaan harus diawali dengan niat yang baik dan membuang pikiran dan perilaku yang buruk (Rusdi, Wabula, Goa, \& Ismail, 2020). Pertukaran umum atau generalized exchange menjadi 
konsep utuh dalam menterjemahkan perilaku masyarakat yang mendukung bahwa, tradisi lokal kosek ponjen sebagai pertukaran menghilangkan keburukan.

Hubungan timbal balik pada ritual kosek ponjen dapat dianalisis dengan teori pertukaran sebagai simbol pelepasan kesialan/ keburukan sebagaimana maksud ritual. Paradigma masyarakat Osing yang memiliki kekhasan baik, secara Bahasa dan tradisi lokalnya merupakan bentuk pertukaran sosial (Istiqomah, 2020). Strukturalisme Levi-Strauss menjelaskan dua konsep pemikiran bahwa, pertukaran simbol dapat terjadi dikarenakan faktor Bahasa (language) dan parole yakni, bahasa yang digunakan sehari-hari. Masyarakat Osing memiliki Bahasa yang berbeda dengan kekhasannya yang menjadi penanda atau identitasnya. Hubungan dengan masyarakat melalui Bahasa parole semakin mengukuhkan pada sikap primordialisme yang menjunjung nilai-nilai budaya dari aspek Bahasa.

Hubungan antar masyarakat dengan penanda Bahasa osing merupakan arbiter sebagai dasar bahwa, terjalin hubungan konvensional dengan masyarakat. Masyarakat osing dengan tradisi lokal kosek ponjen dan bahasanya merupakan konsep pemikiran sinkronik dan diakronik. Strukturalisme Levi-Strauss menjelaskan bahwa, diakronik adalah Bahasa yang mendahulukan adanya kebudayaan (Levi-Strauss, 1972). Tutur kata pada ritual kosek ponjen dengan Bahasa Osing adalah budaya kesehariannya yang telah menjadi identitas masyarakat Banyuwangi. Sementara sinkronik adalah materi atau kondisi yang membentuk kebudayaan, dengan demikian kosek ponjen adalah objek materi yang menjadi wacana kebudayaan masyarakat Osing.

Unsur-unsur yang melingkupi Bahasa dan keyakinan masyarakat terhadap tradisi lokal merupakan konsep sintagmatik dan paradigmatic. Konsep Levi-Strauss tentang sintagmatik adalah aspek-aspek penting yang mengusung tradisi lokal kosek ponjen menjadi ruang komunikasi secara linier dilakukan oleh orangtua dan anaknya terakhir atau yang menjadi pengantin. Pada aspek paradigmatik adalah memperlihatkan suatu hubungan tertentu yang saling menguatkan bahwa, kosek ponjen adalah media komunikasi yang menggantikan posisi pasangan pernikahan bahwa, keburukan atau kesialan telah tergantikan dengan kebaikan.

Keyakinan terhadap hubungan timbal balik pada sebuah tradisi lokal yang diusung oleh masyarakat Osing merupakan komunikasi budaya yang tanpa disadari oleh masyarakat. Bahasa Osing yang khas dengan logat verbalnya dapat dianalisis dengan pendekatan languistik yang menghasilkan kebudayaan. Masyarakat Osing yang tidak hanya terkenal dengan Bahasa dan tradisinya juga agamanya yang menganut Islam yang taat. Masyarakat Osing mampu melakukan ragam adaptasi yang membentuk akulturasi Islam dengan kearifan lokalnya dapat menjadi pusat kebudayaan di Indonesia (Rozi \& Taufik, 2020).

Hubungan timbal balik pada konsep Levi-Strauss tentang pertukaran sosial pada tradisi lokal merupakan fenomena budaya yang terus berkembang dan menjadi wacana kebudayaan yang unik. Keragaman tradisi lokal pada masyarakat Osing merupakan keyakinan yang memiliki hubungan timbal balik pada perilaku ritual (Khasbullah, 2018). Pertukaran sosial sebagai hubungan timbal balik dapat memperkuat kebudayaan masyarakat dengan terus menjaga dan melestarikan kearifan lokal sebagai identitasnya.

\section{Kesimpulan}

Masyarakat Osing di Banyuwangi memiliki sinergitas dalam membangun relasi antara masyarakat dan para Kiai pesantren. Dari hulu hingga hilir masyarakat Osing di Banyuwangi mempunyai visi yang sama dalam melestarikan tradisi lokal. Dialektika suku Osing mampu menciptakan relasi sosial dan agama yang dapat memperkuat potensi budaya masyarakat Osing. Karena itu, Sosio-religi masyarakat Osing memperkaya wacana khasanah kebudayaan yang dapat melahirkan sebuah peradaban baru bagi masyarakat Jawa Timur. Kosek ponjen dimaknai sebagai sebuah pengharapan hidup baru dengan tetap mengamalkan ajaran Islam dengan terus berbagi sedekah dari harta yang dimiliki. Tidak ada yang abadi di dunia maka, persiapkan diri dengan bersedekah sebelum kesialan atau keburukan menimpa manusia. Tokoh masyarakat dan Kiai yang berperan dan mendukung pada tradisi kosek ponjen memperkuat identitas budaya suku Osing. Islam senantiasa memberikan ruang kepada umatnya untuk tidak kaku dalam melihat tradisi lokal. 
Akulturasi Islam menjadi jalan efektif untuk melahirkan ragam tradisi yang dapat memperkaya wacana budaya Indonesia.

Mayoritas masyarakat menganggap bahwa praktik Islam lokal dipandang sebagai Islam yang tidak murni atau sikretisme, yang mana tradisi lokal berjalan beriringan dengan ajaran-ajaran agama Islam. Akulturasi terjadi di Indonesia karena Islam bersifat universal kepada tradisi lokal sehingga terjadi suatu penyatuan yang diimplementasi dalam kehidupan masyarakat. Studi ini berkontribusi dalam menyikapi akulturasi budaya sebaiknya mengutamakan sejarah perkembangan Islam di Indonesia, karena pada proses Islamisasi tidak hanya melalui satu arah, salah satunya melalui aspek pernikahan. Hal-hal tersebut yang menyebabkan terjadinya akulturasi budaya sulit dihindari. Studi ini merupakan salah satu contoh akulturasi budaya yang terjadi di Indonesia, dimana dalam implementasinya kedua budaya berjalan berdampingan tanpa menghilangkan tradisi lokal yang ada.

\section{Referensi}

Ainiyah, N. (2016). Islam, Osing Dalam Bingkai Tradisi Dan Kosmologi: Studi Nelayan Kedungrejo-Banyuwangi. LISAN AL-HAL: Jurnal Pengembangan Pemikiran Dan Kebudayaan, 10(2), 205-230. https://doi.org/10.35316/lisanalhal.v10i2.127

al Asyari, M. K. H., \& Sugihartini, N. F. (2019). Religion and Culture. Proceeding: Faqih Asy'ari Islamic Institute International Conference (FAI3C), 1, 102-121.

Anam, S., Ovaleoshanta, G., Ardiansyah, F., \& Santoso, D. A. (2017). Studi Analisis Budaya Permainan Tradisional Suku Osing Kabupaten Banyuwangi. SPORTIF, 3(2), 178-191. https://doi.org/10.29407/js_unpgri.v3i2.11911

Ani, N., Abubakar, A., \& Iqbal, M. (2019). Akulturasi Islam dalam Perkawinan Adat Dayak Ngaju: Sejarah Masyarakat Muslim di Desa Petak Bahandang, Kabupaten Katingan, Kalimantan Tengah. Jurnal Studi Agama Dan Masyarakat, 15(2), 107-117. https://doi.org/10.23971/jsam.v15i2.1624

Arista, A. (2015). Pemberdayaan Bahasa Osing Melalui Pendidikan Non Formal Di Kabupaten Banyuwangi. Tutur: Cakrawala Kajian Bahasa-Bahasa Nusantara, 1(1), 91-98.

Ashley, K. M. (1990). Victor Turner And The Construction of Cultural Criticism: Between Literature And Anthropology. Indiana: Indiana University Press.

Ayubi, A. A. (2014). Analisis Potensi Ekonomi Kabupaten Banyuwangi. Jurnal Ekonomi Pembangunan, 12(1), 1-15. https://doi.org/10.22219/jep.v12i1.3651

Basyir, K. (2018). Makna Eksoteris dan Esoteris Agama dalam Sikap Keberagamaan Eksklusif dan Inklusif. TEOSOFI: Jurnal Tasawuf Dan Pemikiran Islam, 8(1), 218-241. https://doi.org/10.15642/teosofi.2018.8.1.209-232

Beatty, A. (1999). Varieties of Javanese religion: An anthropological account. New York: Cambridge University Press.

Busro, B., \& Qodim, H. (2018). Perubahan Budaya dalam Ritual Slametan Kelahiran di Cirebon, Indonesia. Jurnal Studi Agama Dan Masyarakat, 14(2), 127. https://doi.org/10.23971/jsam.v14i2.699

Busro, B., Yuliyanti, A. Y., Syukur, A., \& Rosyad, R. (2020). Theological Dimensions in Memitu Rituals in Cirebon. Patanjala: Journal of Historical and Cultural Research, 12(2), 227-242. https://doi.org/10.30959/patanjala.v12i2.636

Cholida, D., Wahyuni, S., \& Widodo, J. (2020). Strategi Transformasi Nilai Kewirausahaan Di Pondok Pesantren Mabadi'ul Ihsan Kabupaten Banyuwangi. Jurnal Pendidikan Ekonomi: Jurnal Ilmiah Ilmu Pendidikan, Ilmu Ekonomi Dan Ilmu Sosial, 14(1), 201-207. https://doi.org/10.19184/jpe.v14i1.12035

Cipta, S. E. (2020). Musik Koplo Sebagai Identitas Kelokalan Baru Pada Penggunaan Bahasa Osing Banyuwangi (Berdasarkan Tinjauan Sosio Kultural-Historis). CERMIN: Jurnal Penelitian, 4(1), 78-91. https://doi.org/10.36841/cermin_unars.v4i1.517

De Stoppelaar, J. W. (1927). Balambangsch Adatrecht. Rijksuniversiteit Leiden.

Dewi, A. P. (2018). Sinkretisme Islam Dan Budaya Jawa Dalam Upacara Bersih Desa Di Purwosari Kabupaten Ponorogo. RELIGIA, 21(1), 96-107. https://doi.org/10.28918/religia.v21i1.1503

Fahad, H. A., \& Endrayadi, E. C. (2017). Pengembangan sektor pariwisata di kabupaten Banyuwangi tahun 20022013. Publika Budaya, 5(1), 28-35.

Geertz, C. (1960). The Religion of Java. London: The University of Chicago Press.

Haq, I. H. (2019). Nilai-Nilai Islam Dalam Upacara Adat Pernikahan Sunda. Al-Tsaqafa: Jurnal Ilmiah Peradaban Islam, 16(1), 29-43. https://doi.org/10.15575/al-tsaqafa.v16i1.3562

Hidayatullah, W. (2020). Pola Komunikasi Pada Acara Ritual Ruwatan Potong Rambut Gembel di Dieng Wonosobo. JISIP : Jurnal Ilmu Sosial Dan Ilmu Politik, 9(2), 123-126. https://doi.org/10.33366/jisip.v9i2.2229

Hindaryatiningsih, N. H. (2017). Model Proses Pewarisan Nilai-Nilai Budaya Lokal dalam Tradisi Masyarakat Buton. Sosiohumaniora, 18(2), 100-107. https://doi.org/10.24198/sosiohumaniora.v18i2.9228 
Istiqomah, A. W. N. (2020). Etnopedagogi Tradisi Lisan Basanan Suku Osing di Kecamatan Glagah Kabupaten Banyuwangi Dan Pemanfaatannya Sebagai Buku Ilmiah Populer. Universitas Jember.

Khasbullah, W. setiyani. (2018). Perilaku Ritual Keagamaan Komunitas Tlasih 87 dalam Menciptakan Hubungan Harmonis Antar Umat Beragama. Religió: Jurnal Studi Agama-Agama, 8(1), 139-163. https://doi.org/10.15642/religio.v8i1.750

Kholiq, I. N. (2019). Fast Response Garda Ampuh dalam Penanganan Anak Muda Putus Sekolah di Banyuwangi. Jurnal Darussalam: Jurnal Pendidikan, Komunikasi Dan Pemikiran Hukum Islam, 10(2), 405-423. https://doi.org/10.30739/darussalam.v10i2.382

Kusnadi, K., Sunarlan, S., \& Sariono, A. (2019). Nelayan Osing di Blimbingsari: Sinergitas Antarsektor, Kemiskinan, dan Pengembangan Ekonomi Lokal. Universitas Jember.

Levi-Strauss, C. (1972). Structural Anthropology. New York: Penguin Books.

Levi-Strauss, C. (1989). The Elementary Structures of Kinship. Boston: Beacon Press.

Lubis, H., \& Rohmatillah, N. (2019). Komodifikasi Otoritas Kiai dalam Kontestasi Politik (Studi Komodifikasi Otoritas Kiai di Kecamatan Pasean Kabupaten Pamekasan). Jurnal Sosiologi Pendidikan Humanis, 3(2), 57-64. https://doi.org/10.17977/um021v3i2p57-64

Muasmara, R., \& Ajmain, N. (2020). Akulturasi Islam dan Budaya Nusantara. TANJAK: Journal of Education and Teaching, 1(2), 111-125. https://doi.org/10.35961/tanjak.v1i2.150

Mufrihah, D. Z. (2018). Fungsi Dan Makna Simbolik Kesenian Jaranan Jur Ngasinan Desa Sukorejo Kecamatan Sutojayan Kabupaten Blitar. Mudra Jurnal Seni Budaya, 33(2), 171-181. https://doi.org/10.31091/mudra.v33i2.337

Mukodi, M. (2020). Revitalisasi Islam Nusantara di Era Digital: Antara Harapan dan Kenyataan. INSANCITA, 5(1), 43-54.

Mutawali, M., \& Zuhdi, M. H. (2019). Genealogi Islam Nusantara di Lombok dan Dialektika Akulturasi Budaya: Wajah Sosial Islam Sasak. Istinbath, 18(1).

Najoan, D. (2020). Memahami Hubungan Religiusitas dan Spiritualitas di Era Milenial. Educatio Christi, 1(1), 6474.

Nursafitri, H., Pageh, I. M., \& Wirawan, I. G. M. A. S. (2020). Perubahan Sosial Masyarakat Suku Osing di Desa Kemiren Sebagai Media Pebelajaran Sosiologi. Jurnal Pendidikan Sosiologi Undiksha, 2(3), 180-189.

Nurullaily, Z. Y., \& Faidah, M. (2020). Akulturasi Budaya pada Tata Rias Mupus Braen Blambangan Suku Osing di Desa Kemiren Banyuwangi. Jurnal Tata Rias, 9(1), 195-205.

Oetomo, S. B. (2020). Konflik Penolakan Ritual Doa Leluhur Paguyuban Padma Buana di Pedukuhan Mangir Bantul, Yogyakarta. Jurnal SMART (Studi Masyarakat, Religi, Dan Tradisi), 6(1), 49-62. https://doi.org/10.18784/smart.v6i1.943

Olang, Y., Susanti, Y., \& Risca, M. (2020). Proses Dan Makna Simbol Ritual Munjong Dayak Tobag. ARBITRER: Jurnal Pendidikan Bahasa Dan Sastra Indonesia, 2(1), 213-222. https://doi.org/10.30598/arbitrervol2no1hlm213222

Praditya, P. (2014). Fasilitas kebudayaan Suku Osing di Banyuwangi. EDimensi Arsitektur Petra, 2(2), 32-39.

Rahman, M. T., \& Saebani, B. A. (2018). Membangun Gerakan Inklusivisme Model Jamaah Persatuan Islam. TEMALI : Jurnal Pembangunan Sosial, 1(1), 58-72. https://doi.org/10.15575/jt.v1i1.2488

Ratnawati, I., Triyanto, \& Syakir. (2019). Meanings Possessed by Gajah Oling Batik in Seblang Rituals Performed by Osing Tribe in Banyuwangi. International Journal of Recent Technology and Engineering, 8(2S9), $183-186$. https://doi.org/10.35940/ijrte.B1040.0982S919

Relin, D. E. (2017). Pementasan Tari Gandrung Dalam Tradisi Petik Laut di Pantai Muncar, Desa Kedungrejo, Kec. Muncar, Banyuwangi, Jawa Timur (Suatu Kajian Filosofis). Mudra, 32(1), 41-55.

Rofikoh, S. (2018). Strategi masyarakat Suku Osing dalam melestarikan adat istiadat pernikahan di tengah modernisasi: studi kasus di Desa Kemiren Kecamatan Glagah Kabupaten Banyuwangi. UIN Sunan Ampel Surabaya.

Rozi, S., \& Taufik, Z. (2020). Adaptation of Religion and Local Wisdom in Global Environmental Issues in Indonesia. Religious: Jurnal Studi Agama-Agama Dan Lintas Budaya, 4(3), 191-203. https://doi.org/10.15575/rjsalb.v4i3.9593

Rusdi, M., Wabula, A. L., Goa, I., \& Ismail, I. (2020). Solidaritas Sosial Masyarakat Petani Di Desa Wanareja Kabupaten Buru. Jurnal Ilmiah Mandala Education, 6(2), 20-25. https://doi.org/10.36312/jime.v6i2.1331

Sari, L. R., \& Megasari, D. S. (2020). Tata Laksana Upacara Pernikahan Adat Suku Osing Di Desa Kemiren Banyuwangi. Jurnal Tata Rias, 9(1), 146-155.

Scholte, J. (1927). Gandroeng van Banyuwangi. In Jawa Seri VII. Solo: Java Institut.

Serikit, P. S. R. M. (2009). Pola komunikasi masyarakat OSING (Studi tentang Pola Komunikasi Masyarakat Suku Osing Desa Kemiren Kecamatan Glagah Kabupaten Banyuwangi Jawa Timur). Universitas Negeri Sebelas Maret.

Sulthoni, A., \& Soetopo, D. (2020). Dialektika Bahasa Jawa Dalam Adat Perang Bangkat Suku Osing Kecamatan 
Singojuruh. Khazanah Pendidikan, 14(1), 115-134. https://doi.org/10.30595/jkp.v14i1.8469

Sumbulah, U. (2012). Islam Jawa dan akulturasi budaya: karakteristik, variasi dan ketaatan ekspresif. El-Harakah, 14(1), 51-68.

Syuhadak, S. (2016). Fungsi dan Muatan Nilai-Nilai Budaya dalam Basanan Using Banyuwangi. BELAJAR BAHASA: Jurnal Ilmiah Program Studi Pendidikan Bahasa Dan Sastra Indonesia, 1(1).

Toenlioe, A. J. E., \& Soepriyanto, Y. (2017). Kajian Deskriptif Penyelenggaraan Kurikulum Muatan Lokal Bahasa Using Di SDN 1 Kertosari Banyuwangi. Edcomtech Jurnal Kajian Teknologi Pendidikan, 2(2), 175-178.

Turner, V. (1967). The Forest of Symbols, Aspects of Ndembu Ritual. Ithaca: Cornell University Press.

Yulianingsih, W. (2020). Osing Culture-Based Empowerment of the Millennials in Sapu Jagad Studio Banyuwangi Indonesia. International Journal of Psychosocial Rehabilitation, 24(3), $2523-2533$. https://doi.org/10.37200/IJPR/V24I3/PR201898

Zulfikar, F. (2020). Gastro-Cosmopolitan in Osing Coffee. HISTORIKA, 23(1), 105-118.

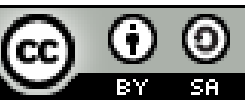

(C) 2021 by the authors. Submitted for possible open access publication under the terms and conditions of the Creative Commons Attribution (CC BY SA) license (https://creativecommons.org/licenses/by-sa/3.0/). 
Halaman ini sengaja dikosongkan 